\title{
DA SEMIÓTICA SOCIAL À MULTIMODALIDADE: A ORQUESTRAÇÃO DE SIGNIFICADOS
}

\section{FROM SOCIAL SEMIOTICS TO MULTIMODALITY: THE ORQUESTRATION OF MEANINGS}

\author{
ZÁIRA BOMFANTE DOS SANTOS * \\ SôNIA MARIA OLIVEIRA PIMENTA **
}

RESUMO: É crescente o interesse pelas pesquisas que investigam a multiplicidade de linguagem, modos ou semioses nos textos em circulação social, seja nos impressos, nas mídias audiovisuais, digitais ou não. A organização estética dos diversos modos semióticos impregna e faz significar os textos contemporâneos. Com o objetivo de propor uma breve discussão em torno da articulação dos modos semióticos na construção de significados dentro dos textos multimodais, este trabalho se ancora nos pressupostos teórico-metodológicos da Semiótica Social e da Multimodalidade preconizados por Hodge; Kress (1988), Kress; Van Leeuwen (1996; 2006)

\footnotetext{
* Pós-doutoranda no Programa de Pós-graduação em Estudos Linguísticos da UFMG - Universidade Federal de Minas Gerais. E-mail: zaira-santos@hotmail.com.

** Docente da UFMG - Universidade Federal de Minas Gerais. E-mail: soniapimenta1@ gmail.com.
} 
e Kress (2010). Para consubstanciar a discussão, é realizada uma análise da orquestração dos significados em uma reportagem da revista feminina Boa Forma, a partir das categorias analíticas da Gramática Sistêmico-Funcional e da Gramática do Design Visual. Na análise, o paralelismo e a intersemiose dos modos semióticos verbais e visuais são evidenciados na construção de significados que tecem o texto.

PALAVRAS-CHAVE: Semiótica Social. Multimodalidade. Metafunção.

ABSTRACT: There is an increasing interest in researches that investigate the multiplicity of language, modes or semiosis in texts in social circulation in printed, digital or audiovisual media. Aesthetic organization of several semiotic modes impregnates and makes contemporary texts mean. Thus, this paper aims to propose a brief discussion on the articulation of semiotic modes in the construction of meanings within the multimodal texts. This work is grounded in the theoretical and methodological assumptions of Social Semiotics and Multimodality postulated by Hodge; Kress (1988), Kress; Van Leeuwen $(1996,2006)$ and Kress $(2010)$. In order to substantiate the discussion, an analysis of the orchestration of meanings in a report found in a women's health magazine, from the analytical categories of Systemic Functional Grammar and the Grammar of Visual Design, is done. In the analysis, the parallelism and the intersemiosis of verbal and visual semiotic modes are evidenced in the construction of meanings that weave the text.

KEYWORDS: Social Semiotics. Multimodality. Metafunction. 


\section{Introdução}

Há, na atualidade, um crescente interesse pela análise de diferentes gêneros discursivos e a multiplicidade de linguagem que utilizam. Os textos que circulam na vida social são altamente multimodais, cada vez mais dialogam com outras interfaces semióticas (BALDRY; THIBAULT, 2005; LEMKE, 2010; KRESS, 2010; ROJO, 2012). Em virtude desse interesse, buscamos fazer, neste trabalho, um breve inventário de contribuições teórico-metodológicas da Semiótica Social e da Multimodalidade para a pesquisa com textos. Para tanto, localizamos, de forma sucinta, historicamente o percurso das escolas semióticas e sintetizamos alguns pressupostos que norteiam a Semiótica Social e a Multimodalidade, e por fim buscamos vislumbrar como esses pressupostos contribuem na apreciação do texto, mais especificamente, analisamos uma reportagem que versa sobre saúde e beleza feminina e como as semioses são utilizadas na construção de significados ideacionais em um periódico que cada vez mais amplia o número de leitores.

\section{A semiótica social}

Em se tratando do desenvolvimento da teoria semiótica, três escolas partiram das ideias do domínio dos estudos em Linguística a fim de adaptá-las aos modos não verbais da comunicação. Segundo resumem Kress e Van Leeuwen (2006), a primeira foi a escola de Praga, que nos anos 1930 e início de 1940 desenvolveu seus trabalhos no campo da arte (Jakobson, Honzl, entre outros) a partir da linguística estudada pelos Formalistas Russos. A segunda foi a Escola de Paris, que nos anos de 1960 e 1970 estendeu as ideias de Saussure para os 
estudos em moda e fotografia (Barthes), cinema (Metz), música (Nattiez), entre outros. Os conceitos desenvolvidos pela segunda escola como "significante", "significado", signos "arbitrário" e "motivado", eixos "paradigmático" e "sintagmático" são até hoje ensinados em cursos relacionados à linguagem e comunicação, recebendo o nome de "semiologia". A terceira escola, denominada Semiótica Social, teve início na Austrália na década de 1980. A Semiótica Social marca o início dos estudos em Semiótica Social aplicada a textos multimodais ao considerar todos os modos semióticos que acompanham o modo verbal, propondo uma nova abordagem calcada na concepção de Halliday (1985), cujo foco está centrado nas funções sociais da linguagem.

Como foco deste trabalho, a terceira escola, a Semiótica Social, marca uma nova fase de estudos, pois tematiza o significado enquanto processo, seguindo as influências dos estudos pós-estruturalistas. Assim, a Semiótica Social tem foco no processo de significação, situando-o como parte da construção social. Para Hodge e Kress (1988, p. 261), a semiótica é "o estudo da semiose, dos processos e efeitos da produção, reprodução e circulação de significados em todas as formas, usados por todos os tipos de agentes da comunicação". A Semiótica Social tem a ver com a semiose humana como um fenômeno social em suas origens, funções, contexto e efeitos. Ela abarca "os significados socialmente construídos através de formas semióticas, textos semióticos e práticas semióticas de todos os tipos da sociedade humana em todos os períodos da história humana" (HODGE; KRESS, 1988, p. 261). As abordagens historicizada e crítica formam a base da Semiótica Social, cujo principal procedimento inclui a exploração e o mapeamento do significado, tendo em conta as dinâmicas culturais e ideológicas nas quais ele está imerso. 
0 ponto central da semiótica é a significação e, para a Semiótica Social, a ênfase recai sobre o processo de produção e recepção do signo. Partindo desse pressuposto, na Semiótica Social o foco está na "forma como as pessoas usam os recursos semióticos para produzirem artefatos comunicativos e eventos para interpretá-los - que é uma forma de produção semiótica - no contexto de situações sociais e práticas específicas" (VAN LEEUWEN, 2005, p. xi).

Essa abordagem enfatiza o conceito de signo na sua produção, formas de articulação e interpretação. Com novos paradigmas, a Semiótica Social trabalha com a discussão de princípios semióticos amplos, dentre os quais destacamos: 1) a noção de escolha do sistema de linguagem; 2) as configurações de significado a partir do contexto; e 3) as funções semióticas da linguagem segundo a Linguística Sistêmico-Funcional - ideacional, interpessoal e textual. Para os autores da Semiótica Social, a noção de escolha é fundamental, pois parte-se do pressuposto de que "os interesses de quem produz um signo levam a uma relação motivada entre significante e significado e, portanto, a signos motivados" (KRESS; LEITE-GARCIA; VAN LEEUWEN, 2001, p. 375). Dessa forma, quem produz um signo escolhe o que considera ser a representação mais apropriada do que se quer significar, ou seja, o interesse orienta a seleção dos atores sociais guiados pelos meios formais de representação e comunicação. Essa formulação garante uma diferença reveladora entre a semiótica convencional e a Semiótica Social, aproximando esta última das leituras dos processos ideológicos e de poder, tomando a dimensão de análises políticas, historicizadas e críticas, pois procura desvendar os caminhos seguidos pelos produtores e pelos interpretantes dos textos, com base em suas escolhas e seus interesses.

Tais princípios semióticos amplos - escolha, contexto e 
funções - são articulados a partir das formulações teóricas de Michael Halliday (1978), que tematizou a linguagem a partir de uma visão sociossemiótica, traçando uma gramática específica, a Gramática Sistêmico-Funcional. 0 ponto central desta discussão repousa na ideia de que a linguagem é um tipo de comportamento social, ou seja, ela tem uma "função" que é construída a partir das interações humanas e está organizada em "sistemas" contextualmente sensíveis. Assim, o uso da linguagem está revestido por significados potenciais, associados a situações específicas e influenciados pela organização social e cultural.

A análise dos processos semióticos pressupõe o entendimento do que seja mensagem, ato semiótico e texto. Para Hodge e Kress (1988, p. 05) "a mensagem tem direcionalidade - ela tem uma origem e uma meta, um contexto social e um objetivo". A mensagem é orientada pelo processo semiótico, ou seja, o processo social no qual o significado é estruturado e trocado. Os autores referem-se a este plano como semiósico. Em outro plano - plano mimético -, a mensagem funciona como representação. 0 significado deriva da função representativa ou mimética que a mensagem desempenha e do processo social no qual ele ocorre.

Hodge e Kress (1988) comentam que a semiose não pode ser definida como a acumulação de mensagens, pois há um movimento de ir e vir entre os participantes no ato semiótico, ou seja, uma tessitura de significados na qual o texto e o discurso estão incluídos. Como já foi dito, esses autores utilizam o conceito de texto de forma extensa, referindo-se a ele como fato socialmente atribuído e com formatação multimodal. Isso significa dizer que, para a Semiótica Social, dois níveis são particularmente importantes: a representação e a comunicação. No nível da representação, ocorre um complexo processo de produção, na medida em que este último pode 
ser considerado como o resultado da história cultural, social e psicológica de quem produz o signo. A representação é

[...] um processo no qual o produtor de um signo, seja adulto ou criança, tenta fazer a representação de algum objeto ou entidade seja ele físico ou semiótico, e no qual o seu interesse naquele objeto no ponto de fazer a representação é complexo e acontece conectado com a história cultural, social e psicológica do produtor do signo e focalizado pelo contexto específico no qual o signo é produzido ${ }^{1}$ (KRESS; VAN LEEUWEN, 1996, p. 06, tradução nossa).

Como já vimos, o interesse guia a seleção, ou seja, a escolha de uma representação é pautada por um aspecto suficientemente representativo do objeto em um dado contexto. Ao escolher uma representação, o ator social o faz com referência ao que, no seu entendimento, pode ser considerado o modo mais apto e plausível naquele contexto e naquela cultura. Assim, o processo de representação nunca pode ser considerado como o objeto em si, mas como um aspecto do que é representado.

O outro nível a ser considerado além da representação é o da comunicação. Se os atores sociais escolhem para representar - seguindo a sua motivação - o que consideram a forma mais apta e plausível, podemos entender que eles o fazem para que a mensagem seja entendida no contexto em que ela acontece. As escolhas, isto é, as formas de expressão dos atores sociais são ativadas a partir do que eles consideram ser mais transparente naquele contexto e naquela cultura.

Kress e Van Leeuwen (2001, p. 20) definem comunicação

$1[\ldots]$ representation as process in which the maker of signs whether child or adult, seek to make a representation of some object or identity, whether physical or semiotic, and in which their interest in the object, at the point of making the representation is a complex, arising the cultural, social, psychological history of the sign-maker, and focused by the specific context in which the sign is produced. 
como "um processo no qual um produto ou evento semiótico é ao mesmo tempo articulado ou produzido e interpretado ou usado". Nesse modelo em que a articulação e a interpretação se conjugam, a comunicação depende da "comunidade interpretativa” (KRESS; VAN LEEUWEN, 2001, p. 08), ou seja, é necessário que o interpretante tenha conhecimento semiótico para entender uma mensagem. A comunicação não acontece somente no polo do produtor, mas depende também do interpretante.

No caso deste trabalho, as leituras sobre as orquestrações da multiplicidade de linguagens na construção de significados revelam um padrão do que é realmente adequado em termos do que é considerado belo e saudável na modernidade.

\section{A abordagem multimodal}

O campo da multimodalidade pretende explorar a produção de significados, levando em consideração os vários modos e meios possíveis de significação à disposição dos atores socioculturais. Na perspectiva de Cope e Kalantzis (2006) todo texto é multimodal, não podendo existir em uma única modalidade, mas tendo sempre uma dela como predominante. Esse é o ponto comum de todos os trabalhos da área, que explora os arranjos de significados, ou seja, investiga o trabalho intersemiótico em questão. Smith et al. (2009) propõem nomear tal modelo como a investigação da orquestração de significados, que supõe, portanto, a abertura do campo analítico da multimodalidade. Dentro dessa perspectiva, para Kress (2010), vários Modos Semióticos (linguagem, imagem, música, gestos, arquitetura, dentre outros) que são realizados a partir de várias modalidades sensoriais (visual, auditiva, tátil, olfativa, gustativa e cinética) passam a ser considerados como participantes do denominado fenômeno multimodal. 
No panorama da orquestração de significados, considerado a partir da multimodalidade, o conceito de modos se torna central:

Modos são recursos semióticos socialmente enquadrados e culturalmente dados para produzir significado. Imagem, escrita, layout, música, gestos, fala, imagem em movimento, trilha sonora e objetos em 3D são exemplos de modos usados na representação e na comunicação ${ }^{22}$ (KRESS, 2010, p. 79, tradução nossa).

Para Kress e Van Leeuwen (2001), a multimodalidade é um campo de estudos interessado em explorar as formas de significação modernas, incluindo todos os modos semióticos envolvidos no processo de representação e comunicação. De acordo com Kress e Van Leeuwen (2001, p. 04), os textos multimodais são vistos como produção de significado em múltiplas articulações. Nesse viés, devido à multiplicidade de conhecimentos constituídos em uma estrutura social, os autores apontam três domínios nos quais o significado é organizado - numa referência à Linguística Sistêmico-Funcional: o design, a produção e a distribuição.

O design situa-se entre o conteúdo e a expressão, ou seja, “é o lado conceitual da expressão e o lado expressivo da concepção" (KRESS; VAN LEEUWEN, 2001, p. 05). Design é o uso do recurso semiótico em todos os modos semióticos e combinações de modos semióticos, formas de expressão dos discursos no contexto de uma dada comunicação. Por outro lado, os discursos tomam forma a partir dos modos semióticos expressos (design) e que têm o potencial de significação destes (dos discursos).

A produção é o uso comunicativo do meio e dos recursos

2 Modes is a socially shaped and culturally given semiotic resource for making meaning. Image, writing, layout, music, gesture, speech, moving image, soundtrack and 3D objects are examples of modes used in representation and communication. 
materiais. É o trabalho físico seja por humano ou máquinas, um trabalho físico de articular texto. Segundo os autores, é a organização da expressão ou do meio de execução do que foi elaborado do design. O meio de produção está intimamente associado com os diferentes canais sensoriais, porque cada meio está caracterizado por uma configuração particular de qualidade material, e cada uma destas qualidades materiais está ligada por um conjunto particular de órgãos sensoriais. Para Kress e Van Leeuwen (2001, p. 66), a produção pode também estabelecer "correspondências" entre a qualidade material percebida por diferentes órgãos sensoriais.

Em relação ao estrato da distribuição, Kress e Van Leeuwen (2001) afirmam que ele tende a ser considerado como não semiótico, pois ele se refere, em um primeiro nível, às tecnologias que podem ser usadas na preservação e transmissão da comunicação. Em um segundo nível, a distribuição tem o objetivo de transformar a comunicação, pois pode criar novas representações e interações, estendendo o significado semiótico e, consequentemente, mudando-o.

A partir desses estratos - discurso, design, produção e distribuição -, a multimodalidade tematiza a forma como o significado se organiza, como pode ser expresso por diferentes modos semióticos e quais semióticas produz. Por esta razão, esse campo teórico enfatiza que o processo de produção de significado, mais do que o significado enquanto núcleo em si mesmo, se torna o foco das análises, pois interessa investigar o que, com qual modo e como o significado foi processado, pois todos esses níveis contribuem para sua articulação e interpretação.

\section{As funções semióticas da linguagem}

Ao proporem uma visão sociossemiótica da linguagem, Kress e Van Leeuwen (2006) centram-se na noção de função preconizada por Halliday (1978). Essa noção é vista como o papel 
que a linguagem desempenha na vida dos indivíduos, servindo aos muitos e variados tipos de demanda. A linguagem se desenvolveu para satisfazer as necessidades humanas, e o modo como ela é organizada é funcional com respeito a essas necessidades.

Por entender que a linguagem se organiza em torno de um propósito - uma função - Halliday (1978) estabelece para os componentes funcionais da língua três metafunções: (1) metafunção ideacional, (2) metafunção interpessoal, (3) metafunção textual, as quais, segundo o linguista, dão conta dos modos de usos da linguagem. $\mathrm{O}$ autor ainda pontua que essas metafunções não atuam de forma isolada, mas interagem na construção do texto conferindo-lhes um caráter multifuncional.

No plano verbal, a metafunção ideacional está relacionada com a dimensão da realidade contida em um texto, ou seja, entre o texto e o mundo real. É através dela que expressamos percepções do mundo ou, em outras palavras, é por meio dessa função que o falante e o ouvinte organizam e incorporam na língua sua experiência dos fenômenos do mundo real, o que inclui sua experiência dos fenômenos do mundo interno da consciência.

A linguagem é usada para interagir com as pessoas, para falar sobre o mundo externo (representado por coisas, eventos e qualidades), interno (relacionando-se aos pensamentos, crenças e sentimentos) e se insere na dinâmica da transitividade, permitindo-nos entender quais Processos são realizados através de grupos verbais na oração e quais Participantes constituídos por grupos nominais estão presentes na ação. O Processo é o componente central da mensagem na perspectiva experiencial.

As escolhas dos Processos, mesmo que intuitivas, sem intenção prévia, são reproduzidas na linguagem, justificando a necessidade de separá-las em categorias. Na Gramática SistêmicoFuncional (GSF) os Processos são divididos em três principais grupos: (i) Processos Materiais - processos que descrevem o 
fazer, ou seja, os acontecimentos e ações físicas no mundo material; (ii) Processos Mentais - relacionam-se ao mundo interior (cognição, percepção, emoção e desejo) tendo o potencial de projetá-lo; (iii) Processos Relacionais - estabelecem relação de ter e ser entre dois participantes. As orações relacionais servem para caracterizar e identificar. Este processo relaciona um Participante a uma identidade ou ao pertencimento de classe.

Halliday e Matthiessen (2004) ainda acrescentam que no limite entre o Processo Material e Mental estão os Processos Comportamentais, que representam as manifestações exteriores de trabalhos interiores - a atuação dos Processos de consciência - e estados fisiológicos. No limite entre os Processos Mentais e Relacionais está a categoria dos Processos Verbais, que expressam relações simbólicas construídas na consciência humana e representadas na forma da linguagem. E no limite entre os Processos Relacional e Material estão os processos Existenciais, que dizem respeito à existência de fenômenos de todos os tipos. $\mathrm{O}$ esquema abaixo sintetiza essas informações:

Esquema 1 - Os tipos de processos.

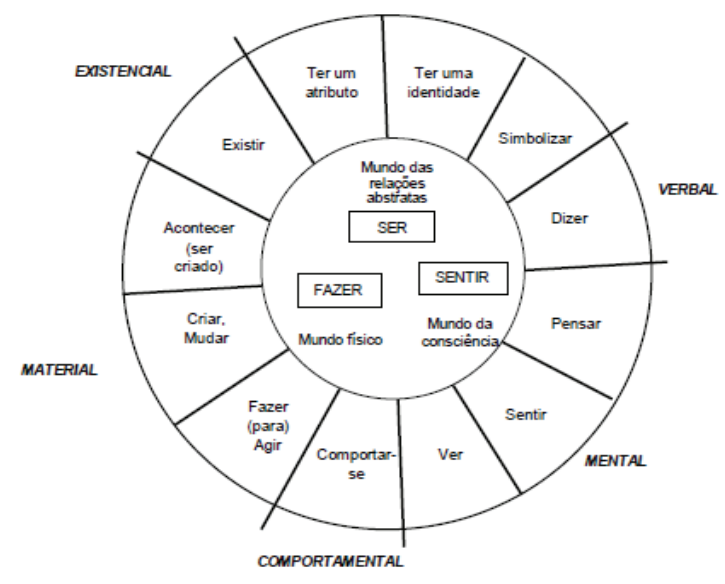

Fonte: Halliday e Matthiessen (2004, adaptado) 
A metafunção interpessoal está relacionada com o aspecto da organização da mensagem como um evento interativo que envolve falante, escritor e público. Centra-se nas relações de troca da oração. Ela permite ao falante participar do evento da fala, fazendo com que ele crie e mantenha relações sociais. É através desta função que os falantes expressam suas opiniões, julgamentos e atitudes. Esta metafunção é interacional e pessoal, constituindo um componente da linguagem que serve para organizar e expressar tanto o mundo interno como o mundo externo do indivíduo. No processo de interação lançamos mão de diferentes papéis de fala. Os papéis de fala mais fundamentais são: dar e demandar, em ambos o falante dá alguma coisa ao ouvinte (informação) ou requer algo.

A metafunção textual se ocupa do uso da linguagem na organização do texto (oral ou escrito). Assim, a oração, concebida como uma unidade na qual os significados de diferentes tipos são combinados, é organizada em torno da estrutura Tema/Rema e Dado/Novo. O elemento tema serve como ponto de partida da mensagem que orienta e situa a oração dentro do contexto. Assim, sendo o primeiro constituinte da oração, todo o restante da oração denomina-se rema. Quanto à informação semântica contida no texto distribui-se pelo menos em dois grandes blocos: dado e novo, cuja disposição interfere na construção do sentido. A informação dada - aquela que se encontra na consciência dos interlocutores e pode ser recuperada pelo contexto - estabelece pontos de ancoragem para aporte da informação nova.

Baseados no princípio metafuncional, Kress e Van Leeuwen (2006) defendem que as estruturas visuais assemelham-se às estruturas linguísticas, visto que aquelas também expressam interpretações particulares da experiência, além de se constituírem como formas de interação social. Desse modo, as escolhas de composição de uma imagem também são escolhas de significados: 
Significados pertencem à cultura, ao invés de modos semióticos específicos [...]. Por exemplo, aquilo que é expresso na linguagem através da escolha entre diferentes classes de palavras e estruturas oracionais, pode, na comunicação visual, ser expresso através da escolha entre os diferentes usos de cor ou diferentes estruturas composicionais. E isso afetará o significado. Expressar algo verbalmente ou visualmente faz diferença $^{33}$ (KRESS; VAN LEEUWEN, 2001, p. 02, tradução nossa).

Kress e Van Leeuwen $(1996,2006)$ entendem que as imagens se articulam em composições visuais também produzindo significados ideacionais, interpessoais e textuais. Extrapolando o foco da Gramática Sistêmico-Funcional na linguagem verbal, os autores formulam a Gramática do Design Visual (doravante GDV), estabelecendo uma perspectiva multimodal que envolve os significados de imagens e diagramas. Neste viés, os significados representacionais, os interativos e os composicionais operam simultaneamente em toda imagem, construindo padrões de experiência, interação social e posições ideológicas a partir das escolhas de qual realidade está sendo representada.

\section{A perspectiva metafuncional nas composições visuais}

Por entender a correlação de significados entre o plano verbal e visual, Kress e Van Leeuwen $(1996,2006)$ delineiam como o princípio metafuncional se dá no plano visual:

3 Meanings belong to culture, rather than to specific semiotic modes [...]. For instance, what is expressed in language through the choice between different word classes and clause structures, may, in visual communication, be expressed through the choice between different uses of color or different compositional structures. And this will affect meaning. Expressing something verbally or visually makes a difference. 
Quadro 1 - As metafunções no plano visual.

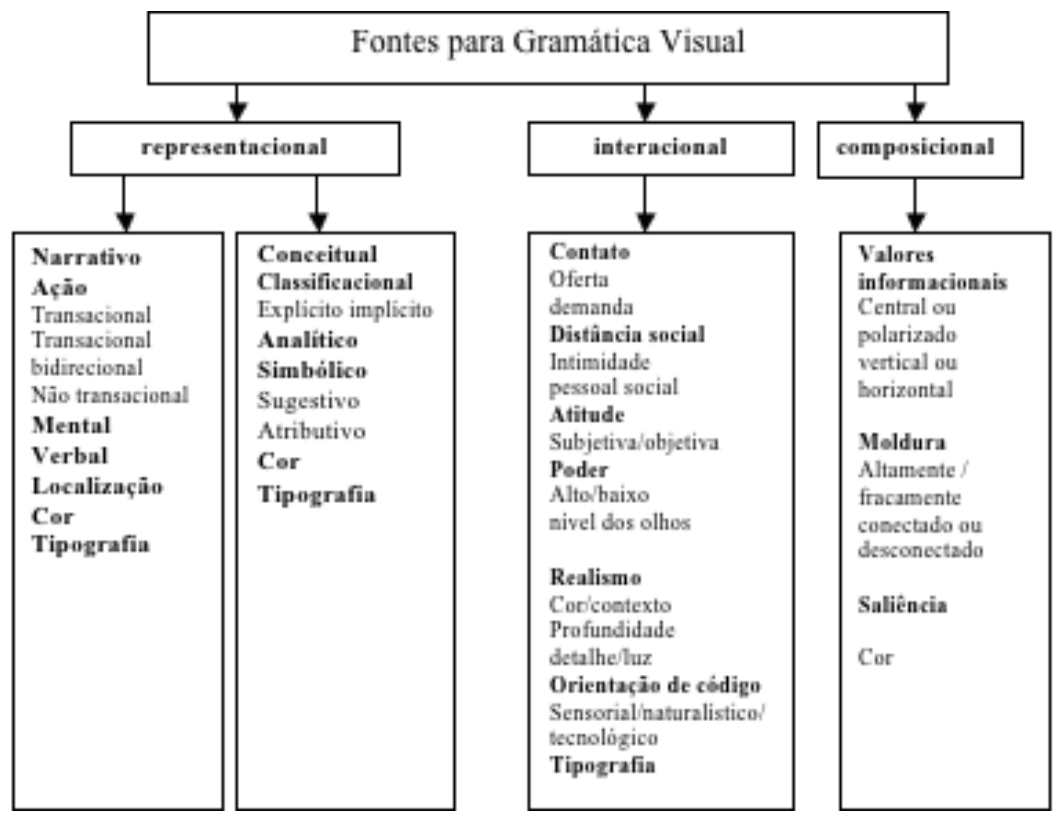

Fonte: Kress e Van Leeuwen (1996, 2006, adaptado)

A metafunção representacional no visual se organiza em torno de estruturas narrativas e conceituais. O que caracteriza uma estrutura narrativa visual é a presença de um vetor, de um traço que indique direcionalidade. De acordo com o tipo de vetor e com o número de participantes envolvidos no evento, é possível distinguir seis tipos de processos narrativos: os processos de ação, os processos reacionais, os processos de fala e mentais, os processos de conversão e o simbolismo geométrico.

As estruturas conceituais representam os participantes em termos de sua essência e podem ser construídas por meio de três tipos de processos: os processos classificacionais, os processos analíticos e os processos simbólicos. No processo 
classificacional, não há vetores. Ele relaciona os participantes em termos de relações de classe taxionomicamente. Nos processos analíticos, a relação entre participantes é representada segundo uma estrutura de parte e todo, sendo um deles o Portador (o todo) e o(s) outro(s) o(s) Atributo(s) Possessivo(s) (as partes). Nesse tipo de processo apresentam-se somente os traços essenciais dos Atributos Possessivos, que geralmente são nomeados. Há ainda um terceiro tipo de processo conceitual: os processos simbólicos. Estes se referem ao que o participante significa ou é, o participante que é significado é o portador, já o participante que representa o significado é o atributivo simbólico.

No que se refere à metafunção interpessoal no visual, ela se revela através de algumas categorias:

$\checkmark$ Contato- marca uma maior ou menor interação com o leitor. Podem-se classificar as imagens a partir da expressão/modo semiótico do olhar, como sendo demanda e oferecimento - atos de imagens. Um ato é uma unidade de significado, são corpos posicionados num determinado local e num determinado tempo.

$\checkmark$ Distância ou afinidade social - realizada pelo tamanho da moldura e tipos de enquadramento, pode codificar uma relação imaginária de maior ou menor distância social.

$\checkmark$ Atitude - é a dimensão que revela a perspectiva da imagem, o ângulo ou o ponto de vista a partir do qual os participantes representados são retratados, indica uma atitude mais ou menos subjetiva por parte do produtor da imagem.

A metafunção composicional é configurada a partir de:

$\checkmark$ Valores informacionais - colocação do que se pode chamar de zonas da imagem, que seriam os planos superior e inferior, as margens direita e esquerda e o centro da imagem. Os elementos localizados à esquerda da página são apresen- 
tados como Dado, e os elementos à direita são o Novo. Algo é concebido como Dado quando apresentado como já conhecido do leitor. 0 Novo é o espaço destinado à apresentação da informação nova, a questão a ser discutida.

Moldura - refere-se aos elementos ou grupos de elementos que podem ser conectados ou separados uns dos outros. De acordo com a gramática do design visual, há várias formas de se realizar a moldura, sendo a presença de linhas, de contorno, de descontinuidades de cor e de espaços vazios entre os elementos. Por outro lado, a presença de vetores pode reforçar a conexão, e estes podem ser realizados por elementos da composição ou por elementos gráficos abstratos.

$\checkmark$ Saliência - se dá na configuração dos elementos com a finalidade de atrair a atenção do leitor em diferentes graus máxima ou mínima - realizados por fatores como localização no primeiro ou segundo plano, tamanho, perspectiva, contrastes de tonalidade ou cor, diferenças de brilho.

Na perspectiva de Kress e Van Leeuwen (2006), a tipografia e a cor são fontes semióticas multimodais com a função comunicativa de representar ideias, atitudes e estabelecer coerência, ou seja, carregam significados representacionais, interpessoais e composicionais.

A partir dessas categorias propostas por Kress e Van Leeuwen $(1996,2006)$, baseadas no princípio metafuncional, é possível vislumbrar como os recursos semióticos simultaneamente dispõem de ferramentas para a construção de significados ideacionais e interpessoais. A abordagem sistêmico-funcional está interessada nos significados potenciais dos recursos semióticos distribuídos em extratos - contexto, discurso, léxico-gramática, fonológico e grafológico e a análise dos significados integrados com as escolhas semióticas no discurso multimodal. Assim, na seção seguinte, analisamos a 
orquestração dos significados ideacionais/representacionais, considerando a articulação dos modos semióticos do plano verbal e visual na constituição de um discurso que busca representar o tema beleza e saúde.

\section{A orquestração dos significados ideacionais no plano verbal}

Escolhemos para analisar nesta seção uma reportagem de capa da revista Boa Forma. Essa escolha é motivada devido ao grande consumo desse material e a utilização de diversos recursos semióticos na orquestração de significados bem como a veiculação de um discurso imperativo de beleza e corpo.

O corpo feminino tem sido, ao longo da história, objeto de profundas transformações, servindo aos interesses culturais de cada época. Nesse sentido, podemos afirmar, segundo Goellner (2003), que a preocupação com o corpo constitui-se em uma forma de controle social. Esse controle em relação ao corpo é diariamente reforçado pelos meios de comunicação. "Estar na moda", ser vista como "bela" e ser socialmente aceita significam ser magra, ter um corpo delineado. Assim, centramos a nossa análise na orquestração dos significados ideacionais que constituem o texto no seu aspecto representacional.

Contextualizando Boa Forma ${ }^{44}$, ela é um periódico de publicação mensal, da editora Abril, destinado ao público feminino. Possui aproximadamente 1.740 .870 leitores, com uma tiragem mensal (média) de 281.020 de exemplares, com circulação líquida de 204.830 exemplares. É definida pela junta editorial como uma revista que se propõe a ajudar a mulher

4 Todas as informações sobre Boa Forma foram coletadas no editorial da revista, disponível em: <http://publicidade.abril.com.br >. Acesso em: 25 mai. 2013. Fonte: Projeção Brasil de Leitores Ed. Abril - com base nos estudos Marplan/IVC, consolidados em março de 2012. 
brasileira no cuidado com a forma, beleza e também a saúde a partir da consultoria dos melhores experts do país. É um traço característico da revista trazer em cada edição a figura de mulher conhecida, bem sucedida, representada como símbolo de corpo saudável, definido e belo.

A partir dessas informações, fizemos um mapeamento das ocorrências dos modos semióticos presentes, bem como os processos encontrados no plano verbal e visual e como é construída a orquestração para representação dentro da reportagem. De acordo com Goellner (2003), falar do corpo é falar em linguagem, já que o corpo é também o que dele se diz. A linguagem não só reflete os corpos reais como tem o poder de criar modelos de corpos considerados adequados. Nesse sentido, voltamos nosso olhar sobre como a noção de beleza, corpo saudável é construída multimodalmente.

A reportagem selecionada traz a modelo Gisele Bündchen como participante central dentro da edição, descrevendo seus hábitos alimentares, esportivos, de cuidados com a beleza e rotinas, através dos vários domínios experienciais:

Tabela 1 - A escolha dos Processos em Boa Forma.

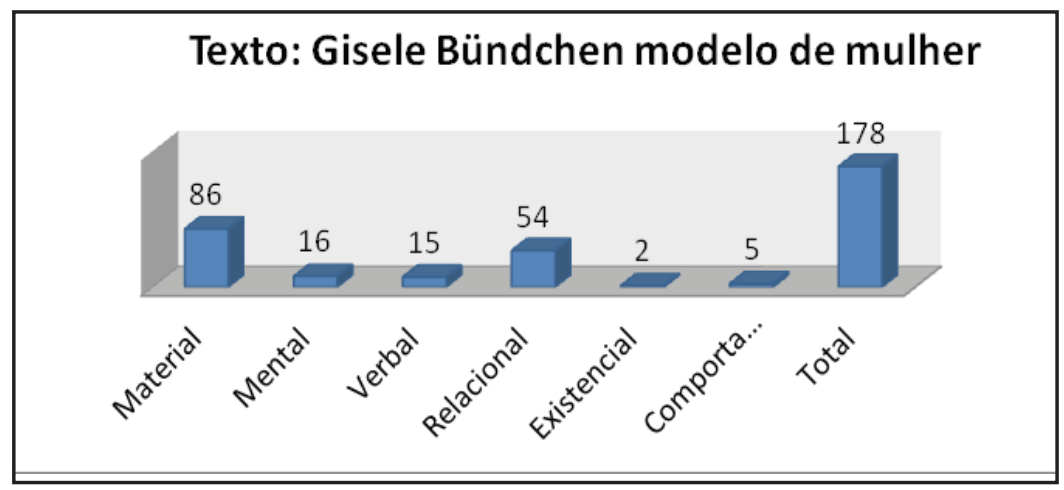

Fonte: Elaboração própria 
A participante, através dos processos materiais, desempenha uma série de ações no seu comportamento diário, relacionadas aos hábitos alimentares (escolher, praticar, usar etc.), que lhe garante saúde e boa forma/beleza:

(1) Também, [ator] procuro escolher [processo material] alimentos mais nutritivos [meta] que me deem energia, explicou.

(2) [ator] Pratico [processo material] hatha ioga [meta] há mais de dez anos e [ator] continuei [processo material] durante toda gravidez. [circunstância]

(3) [circunstância] No rosto [ator] uso [processo material] um hidratante [meta] de manhã e outro a noite. [circunstância]

(4) [ator] Pratico [processo material] Kung fu [meta] quando estou em Boston, [circunstância] já em Los Angeles [ator] faço [processo material] aulas de dança e também um pouco de musculação [meta].

Nas escolhas sistêmicas, há proeminência de atribuição de qualidades e classificação da participante por meio de processos relacionais. Eles constituem uma força argumentativa eficaz na construção significativa do evento, definindo e classificando a participante materialmente construída. Os processos relacionais descrevem Gisele através de atributos altamente qualificados e a identificam como um ícone no cenário feminino:

(5) Ela [Portador] é [processo relacional atributivo] 
linda, rica e bem sucedida... [atributo]

(6) Para mim [Portador] a ioga é [processo relacional atributivo] uma filosofia de vida... [atributo]

(7) A beleza de Gisele [valor] é [processo relacional identificativo] o sonho de consumo de todas nós, principalmente pelo ar natural... [característica]

(8) Gisele [portador: possuidor] tem [processo relacional possessivo] um brilho invejável [atributo possuído] e, como Sansão, seu cabelo [valor] é [processo relacional identificativo] sua força [característica]

(9) [...] como pode, aos 31 anos e com um filho pequeno, [portador: possuidor] ter [processo relacional possessivo] um corpo tão bonito, tão perfeito? [atributo possuído]

(10) Gisele [portador] está [processo relacional atributivo] em sua fase mais feliz, completa. [atributo circunstancial]

A participante é qualificada como linda, rica, bem-sucedida, corpo sequinho, entre outros, que reforçam seus atributos e características, buscando uma identificação com o público leitor por meio de escolhas lexicais altamente selecionadas. As escolhas de transitividade qualificam, descrevem e identificam de forma explícita a participante e o resultado do estilo de vida que adota, podendo ser averiguada a partir da escolha lexical que, além de pontuar os seus atributos, constrói um espaço que privilegia o cuidado com o corpo como símbolo de saúde e beleza. 
Os demais processos ocorrem dentro do texto, em menor recorrência, porém são significativos para marcar os gostos e preferências da modelo. Os processos verbais trazem a voz de Gisele para o texto, constituindo uma forma de a participante revelar com propriedade e autenticidade fatos da sua vida privada, tais como seus hábitos diários que contribuem para sua beleza e bem-estar. Os processos mentais funcionam como um recurso de tentar buscar do leitor uma identificação com o gosto e consumo da top model:

(11) [verbiagem] "Cuido do meu corpo como forma de manter minha saúde e o meu bem-estar. A boa alimentação e a prática de exercícios são fundamentais pra isso", contou [processo verbal] Gisele. [dizente]

(12) [verbiagem] "Hoje em dia como mais peixe e frango, já que diminuí bastante o consumo de carne vermelha. Tenho intolerância a glúten, então evito pães e massas. Também procuro escolher alimentos mais nutritivos, que me deem energia", explicou. [processo verbal]

(13) Faço hidratação em casa com produtos de qualidade e, sempre que posso, [experienciador] prefiro [processo mental] meu cabelo ao natural. [fenômeno]

Em síntese, a distribuição, no plano verbal, dos processos em seus diferentes tipos, associados, na maioria dos casos, à participante Gisele Bündchen, busca representá-la como a imagem de mulher ideal que possui muitos atributos, como se averigua nas imagens do plano visual, a partir de um conjunto de ações que realiza, um comportamento que adota e as preferências que tem para manter a boa forma/saúde/beleza, sendo, assim, identificada 
como estrela, linda, rica, minimalista, bem-sucedida, inteligente e simples.

\section{A orquestração dos significados ideacionais no plano visual}

No plano visual, a reportagem é marcada por imagens, em primeiro plano, da modelo Gisele Bündchen em vários contextos que buscam descrever sua rotina na prática de atividades físicas, no cuidado com a saúde/corpo além da sua beleza. As imagens que descrevem a participante em movimento são marcadas por estruturas narrativas - vetores emergem a partir da posição dos braços e pernas, indicando um conjunto de atividades físicas que ela desenvolve: ioga, Kung fu e esporte ao ar livre:

Imagem 1 - Estrutura narrativa em Boa Forma.

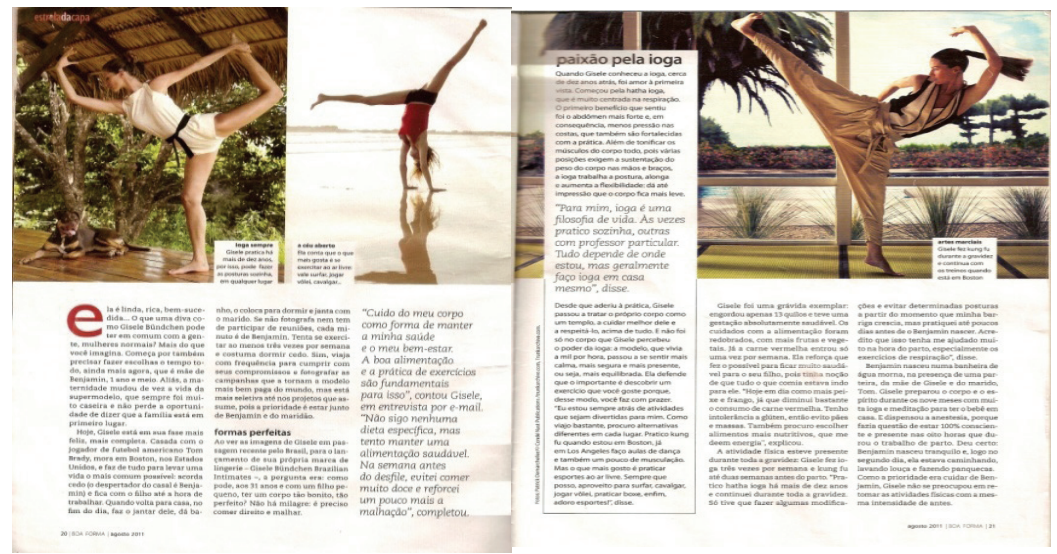

Fonte: Revista Boa Forma, n. 8, ago. 2011

As imagens que constituem a reportagem vão destacando também a beleza e a boa forma de Gisele. Elas se estruturam conceitualmente, a partir de processos analíticos. A modelo se coloca como um item de contemplação, é descrita 
pelos seus atributos possessivos: corpo esbelto, barriga sarada, pele uniforme, cabelos sedosos etc. As imagens, para Sabat (2003), produzem conceitos ou pré-conceitos, formas de ensinar as coisas do mundo, formas de pensar e agir e se relacionar no e com o mundo. Nesse sentido, as imagens veiculadas representam um conceito de beleza e bem-estar ligado a um modelo de corpo esguio, sarado, com curvas acentuadas, uniforme.

Imagem 2 - Estrutura conceitual em Boa Forma.

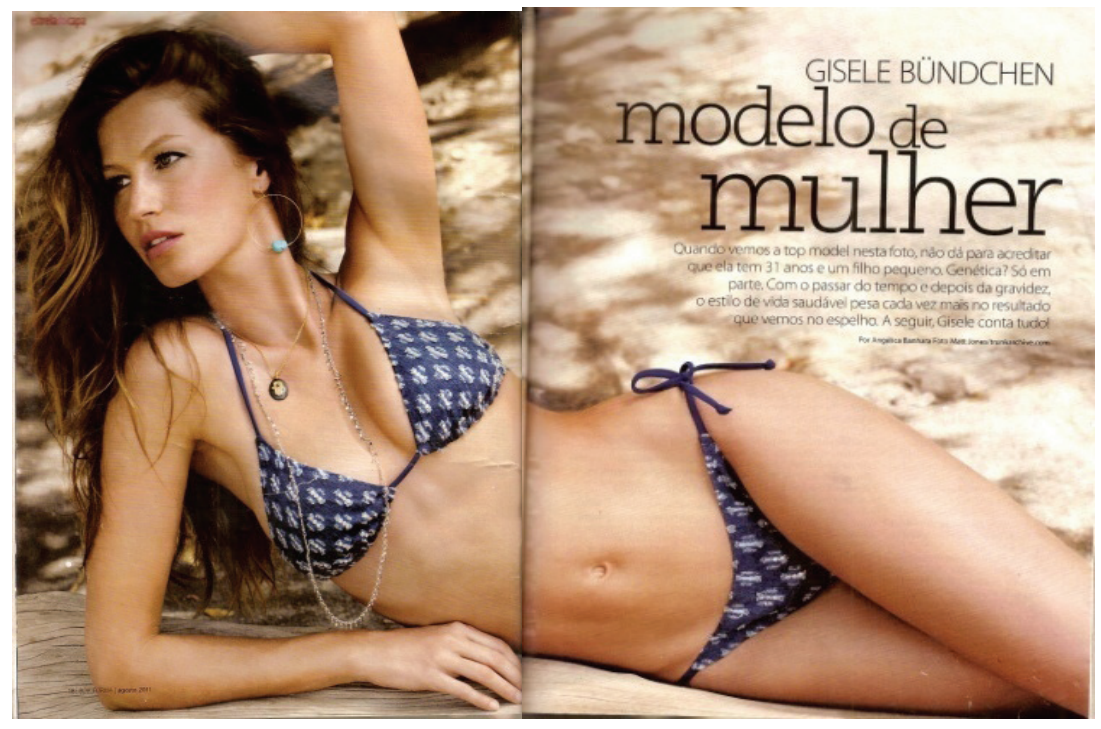

Fonte: Revista Boa Forma, n. 8, ago. 2011

As cores utilizadas na imagem criam harmonia textual e valorizam os atributos de Gisele, através do brilho e dos tons selecionados. Pode-se dizer que, em imagens sensorialmente modalizadas, as cores acrescentam prazer e significados afetivos. A modalidade sensória, portanto, é um recurso para criar imagens que despertam sentimentos subjetivos no leitor, imagens que criam um efeito de hiper-realidade, de forte 
apelo ao imaginário.

A tipografia utilizada na expressão modelo de mulher é marcada por um peso maior dando ênfase ao conteúdo que remete à atuação profissional da participante bem como um modelo a ser seguido. Apoiando-nos em Machin (2007), a tipografia em negrito traz um significado metafórico ideacional de solidez, assertivo, o que converge como significado descrito na semiose visual, através dos atributos positivos: mulher forte, decidida e bela. Além do uso do negrito, a tipografia tem um alto nível de expansão, convergindo para o significado de confidente, remetendo ao que a modelo, por intermédio da reportagem, faz na narrativa ao descrever sua rotina e seu espaço profissional reconhecido.

Imagem 3 - Estrutura conceitual 1 em Boa Forma.

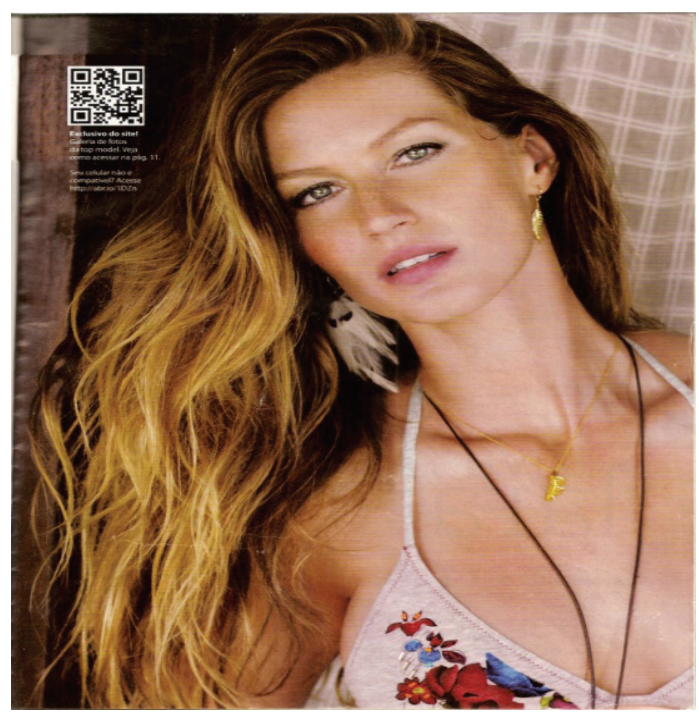

Fonte: Revista Boa Forma, n. 8, ago. 2011

No decorrer da reportagem, vamos identificando os diversos fios semióticos que se colocam como aptos para tecer os 
significados ideacionais na construção de uma representação de mulher bem sucedida, corpo saudável e beleza reconhecida. Esses fios semióticos vão tecendo o texto e construindo uma representação dentro do escopo de revista que Boa Forma se auto define: uma revista que prima pelo cuidado da beleza feminina.

Nas imagens, a recorrência de estruturas narrativas cria um paralelismo/congruência com o plano verbal, perpassando a ideia de que as ações desempenhadas pela modelo deixam o corpo em forma e mais saudável, logo, mais bonito, armando-se a equação: atividades físicas/bem-estar = saúde/beleza. Essa articulação coaduna com as postulações de Castro (2007, p. 67) ao afirmar que saúde e estética são as principais motivadoras para a prática regular de atividades físicas, o que pode ser atribuído à maneira como historicamente os conceitos de saúde e beleza foram sendo construídos e tendo seus sentidos entrelaçados.

Nas estruturas conceituais, marcadas por processos analíticos, há uma valorização dos atributos possuídos de Gisele: cabelos naturais, pele uniforme, boa forma, barriga chapada, curvas acentuadas etc. Ela é representada como uma imagem idealizada - a mulher como a materialização de um ideal de beleza e juventude. Os valores cultuados, ou seja, a preservação da juventude e a promoção da beleza, bem como saúde, ganham legitimidade através da apreciação da sua imagem. Através dessas formas semióticas são reproduzidos significados socialmente construídos de culto ao corpo, padrão de beleza na rede de práticas sociais.

\section{Considerações finais}

A análise multimodal de textos possibilita investigar as formas como os modos semióticos são orquestrados na pro- 
dução de significados. A exploração do potencial desses modos revela como o discurso vai se constituindo. A estética das cores, da tipografia, das imagens, dos processos selecionados na reportagem transforma o texto em um convite - espaço de aparência/demonstração - a partir do equilíbrio entre os recursos verbais e visuais, propiciando atenção do leitor e a representação de um ideal de mulher na concepção da revista Boa Forma: mulher que prima pelo corpo, beleza e saúde.

As imagens são salientes - grandes - colocando os atributos da modelo ao alcance do leitor. "O trabalho com a tipografia e as cores cria uma rima, harmonia visual" (KRESS; VAN LEEUWEN, 1996, p. 217). A repetição de cores e formas em diferentes elementos, no decorrer da reportagem, enfatiza as informações representadas no plano verbal com a promessa do resultado descrito no plano visual. Essa articulação promove o que Kress e Van Leeuwen (2006) denominam intersemiose entre linguagem e imagem, os modos semânticos visuais e verbais se complementam na veiculação de um discurso.

Toda essa articulação confirma como os potenciais dos diversos modos operam em diversos níveis dentro do texto. "A multimodalidade, representações em diversos modos, possibilita e requer a escolha de recursos comunicacionais aptos em todas as situações" (KRESS, 2010, p. 144).

A impossibilidade de apreciar os textos sem desconsiderar as escolhas na produção de significados aponta para a necessidade de trabalhar e compreender o texto tecido por diversos fios semióticos, os quais são escolhidos por uma motivação do seu produtor na veiculação de significados dentro de um contexto social. Essas considerações apontam para a necessidade de ampliação de um olhar sobre os textos que circulam socialmente, na compressão como um construto multimodal. A apreciação multimodal pode possibilitar aos 
leitores refletir sobre a interpretação preferencial e dominante em contraste com a sua própria interpretação. Nas palavras de Rojo (2010), devido à multiplicidade de linguagens e mídias nos textos contemporâneos, a linguagem verbal e outros modos de significar são vistos como recursos representacionais dinâmicos que são constantemente recriados por seus usuários, quando atuam visando atingir variados propósitos culturais.

\section{REFERÊNCIAS}

BALDRY, A.; THIBAULT, P. J. Multimodal Transcription and Text Analysis: A Multimedia Toolkit and Coursebook with Associated On-line Course. London: Equinox Publishing Ltd, 2005.

CASTRO, A. L. Culto ao corpo e sociedade: mídia, estilos de vida e cultura de consumo. 2. ed. São Paulo: Annablume, 2007. COPE, B.; KALANTZIS, M. Changes the Role of Schools. In: COPE, B.; KALANTZIS, M. (Org.). Multiliteracies: Literacy Learning and the Design of Social Futures. New York: Routledge, 2006 [2000]. p. 121-234.

GOELLNER, S. V. A produção cultural do corpo. In: LOURO, G. L. et al. (Org.). Corpo, Gênero e Sexualidade: Um debate contemporâneo na educação. Petrópolis: Vozes, 2003.

HALLIDAY, M. A. K. An Introduction to Functional Grammar. London: Edward Arnold, 1985.

. Language as Social Semiotic. London: Edward Arnold, 1978.

HALLIDAY, M.; MATTHIESSEN, C. An Introduction to 
Functional Grammar. 3. ed. London: Hodder Education, 2004.

HODGE, R.; KRESS, G. Social Semiotics. London: Polity Press, 1988.

KRESS, G.; LEITE-GARCIA, R.; VAN LEEUWEN, T. Semiótica Discursiva. In: VAN DIJK, T. A. El discurso como estructura y processo. Barcelona: Gedisa Editorial, 2001.

KRESS, G.; VAN LEEUWEN, T. Reading Images: The Grammar of Visual Design. London; New York: Routledge, 2006.

Multimodal Discourse: The Modes and Media of Contemporary Communication. London: Arnold, 2001.

Reading Images: The Grammar of Visual Design. London; New York: Routledge, 1996.

KRESS, G. Multimodality: A Social Semiotic Approach to Contemporary Communication. New York: Routledge, 2010.

LEMKE, J. Letramento metamidiático: transformando significados e mídias. Revistas trabalhos em Linguística Aplicada, Campinas, v. 49, n. 2, p. 455-479, 2010. Disponível em <http://scielo.br/scielo>. Acesso em: 10 jun. 2013.

MACHIN, D. Introduction to Multimodal Analysis. London: Hodder Education, 2007.

REVISTA BOA FORMA. São Paulo: Abril, n. 8, ago. 2011. 138 p. ROJO, R. H. R. Multiletramentos: práticas de leitura na contemporaneidade. Disponível em: <http://www.doc.ubi. pt/06/ artigo_sergio_puccini.pdf>. Acesso em: 10 mai. 2013.

SABAT, R. Gênero e sexualidade para consumo. In: LOURO, G. L. et al. (Org.). Corpo, Gênero e sexualidade: um debate contemporâneo na educação. Petrópolis: Vozes, 2003. 
SMITH, B. A.; TAN, S.; PODLASOV, A.; O’HALLORAN, K. L. Orchestration of Meaning in Multimodal Semiosis and Semiotics. Social Semiotics, 2009.

VAN LEEUWEN, T. Introducing Social Semiotics. London: Routledge, 2005.

Artigo recebido em setembro de 2014 e aprovado em dezembro de 2014.

Disponível em: http://seer.fclar.unesp.br/casa 